\title{
MODELAMIENTO KRIGING EN LA TASACIÓN DE PRECIOS PREDIALES URBANOS
}

Grover Marin Mamani, Arnaldo Cahui Galarza, Julio Rumualdo Gallegos Ramos, Néstor Bolívar Espinoza, Vitaliano Enríquez Mamani

\section{RESUMEN}

En la actualidad la necesidad de obtener un predio urbano para construir una unidad habitacional es imperante. El propósito fue determinar el modelo geoestadístico óptimo para la tasación del precio de lotes urbanos en la ciudad de Puno. La metodología aplicada analizó 145 predios en venta los que se dividieron en cuatro zonas urbanas ubicadas por su rumbo, además se usó análisis estructural de datos para las variables área y precio. Los resultados mostraron el área fue de $90,66 \pm 10,63 \mathrm{~m}^{2}$, con respecto a los precios prediales la media fue de 107367,03 $\pm 18772,30$ nuevos soles, la coherencia gráfica del semivariograma para la variable precio es el hole effect con un nivel de confianza de 97,52\%.

Palabras Clave: Geoestadistica, Mapa, Predio, Tasación.

DOI: 10.23881/idupbo.021.1-9i 